\title{
Understanding the physiological changes induced by mannitol: From the theory to the clinical practice in neuroanaesthesia
}

\author{
Wilson Fandino
}

\begin{abstract}
In this narrative review, the current evidence for the use of mannitol in neuroanaesthesia is presented, with focus on its pharmacokinetics and its main physiologic effects. Mannitol is a naturally occurring polyol that undergoes no biotransformation and is freely filtered in the kidney. Due to its strong osmotic effects, it induces key physiological changes, mainly in the cardiovascular system, the kidney and the brain. While it is clear that hypertonic solutions are effective in the treatment of intracranial hypertension in patients with acute brain injury, the role of mannitol in the context of intracranial haemorrhage, acute stroke and brain relaxation remains controversial. Furthermore, it possesses important side effects including acute kidney injury and electrolyte imbalances, particularly related to high doses in predisposing patients. Other aspects including the capability to modify neurological outcomes, the impact on mortality, the utility in patients with disrupted blood-brain barrier and the alternative use of hypertonic saline are also discussed. Further research is needed to make clear recommendations on these aspects.
\end{abstract}

Key words: Intracranial hypertension, mannitol, osmotic diuresis, traumatic brain injury

\section{INTRODUCTION}

Since first introduced in 1940 for exploring the glomerular filtration rate in humans, ${ }^{[1]}$ mannitol has been used in several clinical scenarios. This osmotic agent is useful as a diuretic in the context of crush injury, compartment syndrome and intoxications (e.g., barbiturate, salicylate, bromide), preventing acute renal failure following rhabdomyolysis, and as a hypertonic solution in the treatment of intraocular and intracranial hypertension. It has also been used for exploring the mechanisms of

Department of Neuronaesthesia, The Walton Centre NHS Foundation Trust, Liverpool, United Kingdom

Address for correspondence:

Dr. Wilson Fandino, Department of Neuronaesthesia, The Walton

Centre NHS Foundation Trust, Lower Lane, L9 7LJ. Liverpool,

United Kingdom.

E-mail: wilson.fandino@hotmail.com

\begin{tabular}{|l|l|}
\hline \multicolumn{2}{|c|}{ Access this article online } \\
\hline Quick Response Code: & Website: \\
\hline & www.jnaccjournal.org \\
\hline & \\
\hline
\end{tabular}

tubular reabsorption of water and salt at the nephron, optimising the cardiac preload and contractility, relief of the swelling on the endothelial cell following brief periods of vascular occlusion in heart, kidney and brain, preparation for bowel surgery and as a dialyser in diabetic patients undergoing peritoneal dialysis. ${ }^{[2-4]}$

Mannitol is included in the World Health Organisation's list of essential medicines ${ }^{[5]}$ and has been widely used in neuroanaesthesia, as it is considered to be a safe medication and one of the cornerstones in the treatment of the elevated intracranial pressure (ICP). However, the evidence supporting its use is scarce, the heterogeneity in the dosages used makes it difficult to establish an optimal treatment regimen, the clinical utility in patients with disrupted blood-brain barrier (BBB) is debatable and the impact on the neurological outcomes and mortality remains unknown. Furthermore, it can cause serious

This is an open access article distributed under the terms of the Creative Commons Attribution-NonCommercial-ShareAlike 3.0 License, which allows others to remix, tweak, and build upon the work non-commercially, as long as the author is credited and the new creations are licensed under the identical terms.

For reprints contact: reprints@medknow.com

How to cite this article: Fandino W. Understanding the physiological changes induced by mannitol: From the theory to the clinical practice in neuroanaesthesia. J Neuroanaesthesiol Crit Care 2017;4:138-46. 
complications, particularly related to cardiovascular changes, electrolyte disturbances and renal damage in patients with predisposing factors. Therefore, in this review, the main pharmacologic and physiological effects are revisited, along with the current evidence for its use in neuroanaesthesia, including its utility for the ICP management and brain relaxation.

\section{PHARMACOLOGY}

Mannitol $\left(\mathrm{C}_{6} \mathrm{H}_{14} \mathrm{O}_{6}\right)$ is a naturally occurring 6-carbon polyol, isomer of sorbitol, produced by several microorganisms and plants and found in several fruits and vegetables ${ }^{[4]}[$ Figure 1]. Due to its clinical application in medicine and other fields, it has been industrially manufactured from the hydrogenation of fructose and glucose and from biological sources. ${ }^{[6]}$

As a sugar alcohol, mannitol has a sweet taste. This property has been used by food and pharmaceutical industries for masking bitter tastes. At room temperature, it may crystallise, making it unsuitable for administration. In this case, warming the solution solves the problem. ${ }^{[4]}$ In many countries, $10 \%$ and $20 \%$ solutions are available for clinical use, providing 100 and $200 \mathrm{~g} / \mathrm{L}$, respectively.

Table 1 provides the main physical and pharmacokinetic properties. ${ }^{[2,3,7]}$ Hypertonic mannitol $(20 \%)$ has an osmolarity approximately equivalent to that provided by $3.2 \%$ hypertonic saline. ${ }^{[8]}$ When administered orally, it is minimally absorbed and nearly $75 \%$ undergo fermentation by the intestinal flora. ${ }^{[6]}$ Due to its scanty absorption, it has been used for routine preparation of bowel surgery. When administered intravenously, it distributes primarily in the extracellular compartment and is excreted unchanged in urine. ${ }^{[3,9]}$ Thus, $90 \%$ of the injected dose is recoverable in the urine during the first $24 h^{[9,10]}$

\section{MANNITOL AND THE CARDIOVASCULAR SYSTEM}

The haemodynamic response when administered intravenously is typically triphasic. Approximately 15 min after starting the infusion, it first induces a sharp elevation in the serum osmolarity, resulting in a

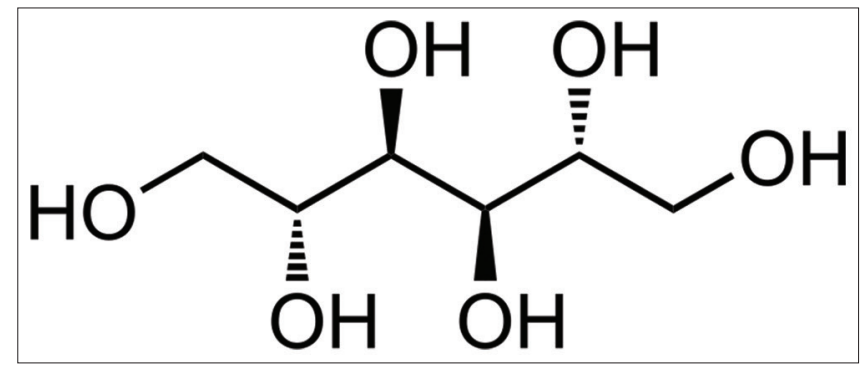

Figure 1: Chemical structure of mannitol transient increase in blood volume, which in turn raises cardiac output (CO) and pulmonary capillary wedge pressure (PCWP) ${ }^{[11]}$ Accordingly, it can elicit cardiogenic and pulmonary oedema in high-risk patients. ${ }^{[2]}$ Therefore, mannitol should be administered cautiously in patients with congestive heart failure or pre-existing renal insufficiency, and when Loop of Henle (LH) diuretics are concomitantly administered. ${ }^{[11]}$ During the second phase, the blood volume, $\mathrm{CO}$ and PCWP drop below initial values after $45 \mathrm{~min}$, due to its diuretic effect and peripheral vasodilation. ${ }^{[11]}$ The latter occurs primarily in the skeletal muscle and leads to marked hypotension, particularly when mannitol is administered at high rates..$^{[11,12]}$ These changes may be also associated with a small increase in blood lactate levels. ${ }^{[13]}$ Finally, during the third phase, these haemodynamic variables return to the baseline values. ${ }^{[11]}$

Since mannitol has a strong diuretic effect, efforts should be made to avoid arterial hypotension ${ }^{[14]}$ and constant monitoring of the cerebral perfusion pressure (CPP) is recommended. Owing to its high osmolarity, when administered through a peripheral line, it can induce phlebitis and skin necrosis may occur in cases of extravasation. ${ }^{[4]}$ Therefore, careful examination of the peripheral vein should be done before, during and after its administration.

\section{MANNITOL AND THE KIDNEY}

Due to its small molecular weight, it is readily filtered in the glomerulus. Then, it decreases the water reabsorption in the proximal tubule, thereby diminishing the sodium concentration. ${ }^{[2,4,9]}$ The water reabsorption also decreases in the descending limb of the LH, whereas the sodium reabsorption is progressively reduced in the ascending limb and the collecting tube. ${ }^{[2]}$

Table 1: Physical and pharmacokinetic properties of mannitol

\begin{tabular}{lc}
\hline Characteristic & Description \\
\hline Molecular weight & 182 Daltons \\
Osmolarity $(20 \%)$ & $1098 \mathrm{mOsm} / \mathrm{L}$ \\
Volume of distribution & $0.471 \mathrm{~L} / \mathrm{kg}$ \\
Onset & $\approx 15 \mathrm{~min}$ \\
Maximal effect & $\approx 45 \mathrm{~min}$ \\
Duration & $\approx 6 \mathrm{~h}$ \\
Half-life & $70-100 \mathrm{~min}$ \\
Biotransformation & None \\
Excretion & Renal \\
Reabsorption & $7 \%$ \\
\hline
\end{tabular}


Although its effects are mainly exerted in the renal tubules, other mechanisms are also important. ${ }^{[2,4]}$ As an impermeant solute mainly distributed in the extracellular compartment, it increases the osmotic pressure, promotes the shift of water out of cells, activates the endogen natriuretic peptides, suppresses the antidiuretic hormone and improves the cortical and medullary blood flow. The marked improvement in the medullary blood flow is also responsible for the dissipation of medullary hypertonicity, leading to tubular inhibition of salt and water reabsorption, excretion of monovalent and divalent cations $\left(\mathrm{Na}^{+}, \mathrm{K}^{+}, \mathrm{Ca}^{++}\right.$and $\left.\mathrm{Mg}^{++}\right)$and anions $\left(\mathrm{PO}_{4}^{-}, \mathrm{HCO}_{3}^{-}\right)$, inability to concentrate or dilute urine and ultimately, osmotic diuresis. These effects, associated with renal vasodilation caused by local release of prostacyclin, are likely to be involved in the protection of kidney injury. ${ }^{[2,4]}$

Under conditions of renal ischaemia, mannitol inhibits the renin-angiotensin system in the renal glomeruli, leading to dilatation of the afferent arteriole and improvement on the glomerular filtration rate in humans and dogs. ${ }^{[2,4]}$ Although these properties have not been found either in normal animal models or healthy volunteers, they have been applied to prevent acute kidney injury (AKI) in some clinical settings, including cardiac and vascular surgery (cardiopulmonary bypass, aortic cross-clamp), renal transplantation (from cadaveric donors), rhabdomyolysis (with creatine kinase levels $>5000 \mathrm{U} / \mathrm{L}$ ) and obstructive jaundice (e.g., cholestatic liver disease). ${ }^{[2,4]}$ During ischaemia-reperfusion, this medication also acts as a free-radical scavenger, reducing the possibility of kidney injury. On the other hand, mannitol can increase oxygen consumption by augmenting the reabsorption of tubular solutes, which in turn improves the glomerular filtration rate. ${ }^{[4]}$

\section{Acute kidney injury}

Mannitol can also induce nephrotoxicity, particularly when serum osmolarity exceeds $320 \mathrm{mOsm} / \mathrm{L} \cdot{ }^{[15]}$ It occurs typically between $12 \mathrm{~h}$ and 7 days (usually within the first $48 \mathrm{~h}$ ) after giving daily or cumulative doses $>200 \mathrm{~g}$ and $1100 \mathrm{~g}$, respectively, ${ }^{[7,9]}$ thereby increasing the osmolal gap more than $55 \mathrm{mOsm} / \mathrm{kg}$ (see below), with typical prompt response to discontinuance of the treatment and haemodialysis, when appropriate. ${ }^{[10,16]}$ It is noteworthy that, whereas low doses increase the glomerular filtration rate acting as a renal vasodilator, higher doses tend to cause the opposite effect. ${ }^{[9]}$

The predisposing factors for nephrotoxicity have been recently identified in patients with acute stroke and intracerebral haemorrhage (ICH). Poor neurological status, concurrent use of diuretics, pre-existing renal impairment, diabetes, higher infusion rates, age $>70$ years and diastolic blood pressure $>110 \mathrm{mmHg}$ have been identified as independent risk factors in two retrospective studies. ${ }^{[7,17]}$

Although the underlying mechanisms of AKI are not thoroughly understood, some of the most accepted theories include:

1. The strong diuretic effect resulting from excessive doses of hypertonic mannitol can lead to peripheral vasodilation -with subsequent haemodynamic changes-, renal vasoconstriction and osmotic nephrosis $(\mathrm{ON})$ in patients with predisposing risk factors, as depicted in Figure 2. ${ }^{[14]} \mathrm{ON}$ has been defined as an isometric tubular vacuolisation, initially accompanied with profound diuresis and natriuresis, and then typically developing oliguric/anuric AKI. ${ }^{[7,9]}$ Cell vacuolisation primarily occurs in the proximal tubules and is caused by the capability of mannitol to cross tubular cells via pinocytosis, forming vacuoles that eventually fuse with lysosomes. ${ }^{[9]}$ Although the subsequent reduction in the proximal luminal diameter is usually reversible, the sequelae of $\mathrm{ON}$ are unpredictable ${ }^{[9]}$

2. In patients with pre-existing chronic kidney disease, mannitol half-life can also increase from 70 to $100 \mathrm{~min}$ to $>36 \mathrm{~h}$, thereby causing nephrotoxicity ${ }^{[7]}$

3. In diabetic patients, the increase in renal blood flow induced by mannitol is unevenly distributed, which results in reduced oxygen delivery to the medulla and predisposes to ischaemic injury ${ }^{[7]}$

4. When diuretics acting at the LH are concomitantly administered, the compensatory enhancement of sodium reabsorption occurring in the LH caused by the increase on water and salt delivery is prevented, resulting in strong diuresis volume depletion and AKI. ${ }^{[8]}$

\section{Fluid and electrolyte imbalances Hyponatraemia}

When plasmatic mannitol concentration increases faster than the renal clearance (e.g., fast load of a high dose of mannitol or renal failure), the serum osmolarity will

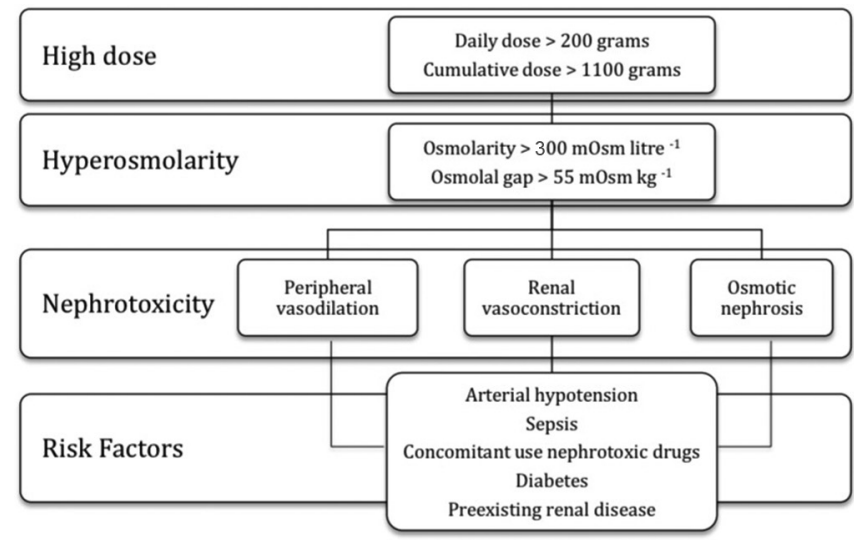

Figure 2: Mechanisms proposed for acute kidney injury related to mannitol infusions 
rise and induce hyponatraemia. ${ }^{[18]}$ In fact, following intravenous administration, for each increase in $100 \mathrm{mg} / \mathrm{dL}$ in the mannitol concentration, the plasmatic sodium will fall between 1.6 and $2.6 \mathrm{mEq} / \mathrm{L}$, as a result of the osmotic load that induces water movement from the intracellular to the extracellular compartment (hypertonic hyponatraemia) ${ }^{[3,19]}$ In addition, for each increase of $182 \mathrm{mg} / \mathrm{dL}$ in its concentration, the serum osmolarity is expected to increase by $10 \mathrm{mOsm} / \mathrm{L}^{\left[{ }^{[3]}\right.}$ Therefore, serum osmolarity should be closely monitored and if it reaches $310 \mathrm{mOsm} / \mathrm{L}$, mannitol should be suspended. ${ }^{[20]}$

Other authors recommend to measure the osmolal gap $(\mathrm{mOsm} / \mathrm{kg})$, particularly in patients with renal impairment. ${ }^{[16,19]}$ The osmolal gap, calculated as the difference between calculated and measured osmolality, can predict the mannitol concentration in blood. Hence, osmolal gaps $>55 \mathrm{mOsm} / \mathrm{kg}$ (i.e., mannitol concentration $>1000 \mathrm{mg} / \mathrm{dL}$ ) should be avoided, since they have been found to cause renal vasoconstriction. ${ }^{[16,19]}$ However, the hyponatraemia appears to be self-corrected within $3 \mathrm{~h}$ after an infusions of up to $1.4 \mathrm{~g} / \mathrm{kg} \cdot{ }^{[13]}$

In cases of induced hyponatraemia and AKI, any attempt to replace the sodium with hypertonic saline infusion will further increase the serum osmolarity. Instead, it should be treated with haemodialysis, when appropriate. ${ }^{[19]}$ In patients with normal renal function, the diuresis caused by mannitol should correct the sodium levels. ${ }^{[21]}$

\section{Hyperkalaemia}

Mannitol has been considered a safe medication when used at low doses $(0.25 \mathrm{gm} / \mathrm{kg}) \cdot{ }^{[22]} \mathrm{In}$ fact, no cases of hyperkalaemia have been reported with the use of low doses administered at slow rate. ${ }^{[2,23]}$ However, it is a potential life-threatening complication ${ }^{[24]}$ and there have been reported cases of intraoperative cardiac arrest, requiring immediate intervention. ${ }^{[2,23,25]}$ When administered along with blood, it can induce haemolysis and hyperkalaemia. ${ }^{[23,24]}$ It can also be caused by the shift of potassium from the intracellular to the extracellular compartment, particularly in patients with renal failure. ${ }^{[2]}$

Although several theories have been proposed to explain the mechanism of hyperkalaemia, including passive potassium movementacross the cell membrane in response to the hypertonic load, dilutional acidosis, haemolysis and strong ion difference, this phenomenon remains poorly understood..$^{[22,23,25]}$ The strong ion difference has been defined as the balance between strong cations $\left(\mathrm{Na}^{+}\right.$, $\mathrm{K}^{+}, \mathrm{Mg}^{+}$and $\left.\mathrm{Ca}^{++}\right)$and strong anions $\left(\mathrm{Cl}^{-}\right.$and lactate). According to this theory, a balance impairment caused by $\mathrm{Na}^{+}$reabsorption decrease stimulates $\mathrm{H}_{2} \mathrm{O}$ dissociation, and hyperkalaemia occurs in response to an increase in the $\mathrm{H}^{+}$concentration. ${ }^{[23]}$ In addition, hyponatraemia may increase the hyperkalaemia-related cardiotoxicity, although the underlying mechanisms have not been completely elucidated. ${ }^{[25]}$ The effects on potassium levels seem to be related with the dose administered. Accordingly, whereas moderate doses $(1 \mathrm{~g} / \mathrm{kg})$ tend to cause mild hypokalaemia, high doses $(2 \mathrm{~g} / \mathrm{kg})$ are associated with hyperkalaemia. ${ }^{[22,23,25]}$

\section{Other electrolyte imbalances}

Hypokalaemic, hypochloraemic alkalosis may be induced by mannitol, following the volume contraction. ${ }^{[26]}$ Metabolic acidosis has also been described, as a result of solvent drag and dilutional acidosis. ${ }^{[10]}$ Repeated administrations, apart from being less effective, can also result in hypernatraemia and hyperosmolarity caused by dehydration and osmotic diuresis, leading to neurologic complications including demyelination syndromes. ${ }^{[3,10]}$

\section{MANNITOL AND THE BRAIN}

Hypertonic mannitol was first used by Scharfetter in 1960 for relieving the ICP. ${ }^{[3,22,23]}$ Although a 20\% solution given intravenously at a dose as low as $0.15-0.20 \mathrm{~g} / \mathrm{kg}$ over 30-60 min has been considered to be safe, it has been used at doses up to $2 \mathrm{~g} / \mathrm{kg}$ in a single administration. ${ }^{[2,9,23]}$

Three mechanisms have been proposed to contribute its capability of lowering ICP ${ }^{[27]}$ [Figure 3]. First, it directly improves the CPP, as a result of the transient increase of the CO occurring during the first minutes of administration. ${ }^{[11]}$ When cerebral autoregulation is preserved, the increase on the CPP leads to cerebral vasoconstriction, thereby diminishing the cerebral blood volume (CBV) and ICP. Second, it increases the cerebrovascular resistance (CVR) caused by reflex vasoconstriction of cerebral arterioles, after an initial improvement in the cerebral blood flow (CBF). The effects on the CVR occur within a few minutes of administration as a result of hypervolaemia, which is caused not only by the improvement in the $\mathrm{CO}$ but also a decrease of the blood viscosity and haemodilution. ${ }^{[14,27,28]}$

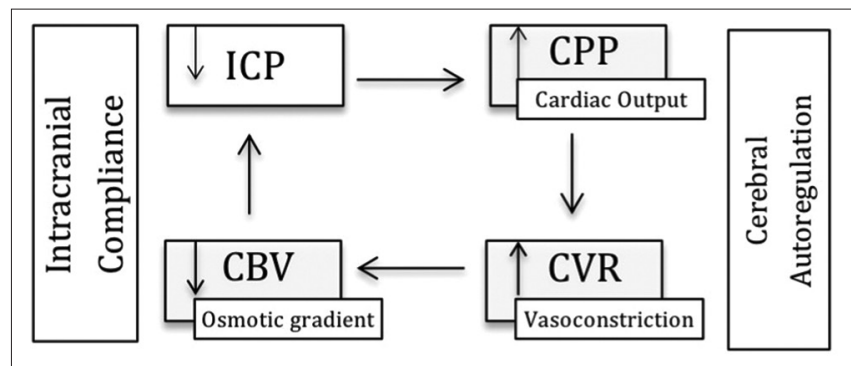

Figure 3: Three proposed mechanisms of mannitol for lowering the intracranial pressure. First, it improves the cerebral perfusion pressure, as a result of the transient increase of the cardiac output. When cerebral autoregulation is preserved, this improvement causes reflex cerebral vasoconstriction, leading to an increase of the cerebrovascular resistance. Finally, the osmotic gradient generated diminishes the cerebral blood volume and improves the intracranial compliance. All these changes lead to a consistent improvement of the intracranial pressure 
These changes are followed by a fall in the CBV, which ultimately decreases the ICP. ${ }^{[29]}$ Finally, mannitol causes a direct impact on the CBV, as it promotes the shift of water from the intracellular to the extracellular compartment, thus alleviating the cerebral oedema [Figure 3].

The effects on the water movement and the improvement on the intracranial compliance eventually lead to an improvement on the ICP. Contrary to the rheological effects, the osmotic effects are delayed for 15-30 min and may last for 1.5-6 h, when the osmotic gradient equilibrates with the development of cerebral idiogenic osmoles (osmotically active substances produced by astrocytes) ${ }^{[14,26]}$ Furthermore, mannitol globally improves the CBF and oxygen delivery not only by increasing the $\mathrm{CPP}$ (caused by an improvement of the $\mathrm{CO}$ and a drop in the ICP) but also diminishing the production and stimulating the reabsorption of cerebrospinal fluid. ${ }^{[28]}$

Although the main mechanisms are related to the shift of water from the white matter into the intravascular compartment, its effects in the human brain can be more complex. For instance, it may also increase the $\mathrm{CBV}$ and worsen ICP when the rate given exceeds the rate filtered in the kidney. ${ }^{[18]}$ However, provided that cerebral autoregulation is preserved, the secondary augment in the CPP may result in vasoconstriction and improvement of the ICP [Figure 2]. In addition, the effects on the CBV are independent of the ICP within the range of $0-25 \mathrm{~cm} \mathrm{H}_{2} \mathrm{O}$, when the intracranial compliance is preserved ${ }^{[27]}$ [Figure 2]. When administered in fast boluses, it causes a dose-related increase of the CBV, both in the grey matter and the large venous sinuses, leading to acute worsening of the ICP. ${ }^{[27]}$

Mannitol has been considered to be impermeant to the BBB. However, a small rebound in the ICP can be noted when the solution occasionally passes into the brain. ${ }^{[3]}$ This is also explained by the generation of idiogenic osmoles, thereby allowing a shift in the gradient of water in the cellular membrane. Therefore, in patients with consistently high ICP requiring prolonged treatment, it has been recommended to carefully wean the hyperosmolar therapy. ${ }^{[30]}$

More importantly, in cases of traumatic brain injury (TBI), $\mathrm{ICH}$ or vasogenic oedema where the BBB has been disrupted, caution should be taken for administering the smallest dose, guided by the ICP monitoring and the neurological status of the patient. ${ }^{[27]}$ Some other authors have suggested to avoid the use of mannitol in this scenario, since the cerebral oedema could be worsened. ${ }^{[4,30]}$

\section{Intracerebral haemorrhage}

The use of mannitol in patients with ICH is not currently recommended, unless there is evidence of symptomatic cerebral oedema and raised ICP. ${ }^{[31,32]}$
Several studies have failed to demonstrate any benefit in this population. ${ }^{[33-35]}$ In a clinical trial involving patients with ICH, no improvement was found in 1-month mortality or functional disability at 3 months, after administering cumulative doses of $700 \mathrm{~g}$ per patient over 1 week, regardless the location and size of the haematoma, ventricular extension or midline shift. ${ }^{[35]}$

From the results of the Intensive Blood Pressure Reduction in Acute Cerebral Haemorrhage Trial (INTERACT2), which included more than 2800 patients with spontaneous ICH and hypertension that were randomised to standard or intensive blood pressure lowering, Wang et al. reported that death or major disability at 90 days were not significantly improved in the mannitol treatment group. ${ }^{[36]}$ Similarly, in another study patients treated with mannitol had worse neurological outcome at 90 days, compared with those untreated. ${ }^{[37]}$ The lack of benefit in this population is likely explained by the fact that this medication can penetrate a disrupted BBB, thereby blunting the osmotic effects and in some cases aggravating the cerebral oedema.

\section{Acute stroke}

Some authors have proposed the use of mannitol as a brain protector in situations of cerebral ischaemia. ${ }^{[38,39]}$ Apart from its positive effects on the CPP, this osmotic agent can also act as a scavenger of hydroxyl radicals, thereby reversing the changes in the BBB permeability and reducing the accumulation of reactive oxygen species in models of ischaemic brain. ${ }^{[27]}$ It has also been used for reducing the ICP in the context of the management of cerebral oedema following a stroke, but no evidence indicates that it can improve the outcome. ${ }^{[38,39]}$

In a multicentre study, a prospective database from patients with ischaemic and haemorrhagic acute stroke admitted within the first 3 days was analysed. ${ }^{[39]}$ The adjusted odds ratio (OR) for survival in the mannitol group was not significantly different from the untreated group at 1 and 12 months, neither in the ischaemic nor in the haemorrhagic stroke group. ${ }^{[39]}$

Furthermore, in a small clinical trial, patients with a large hemispheric infarction and midline shift $>10 \mathrm{~mm}$ had a small reduction in the CBV restricted to the non-infarcted hemisphere, after administering $1.5 \mathrm{~g} / \mathrm{kg}$ of mannitol. ${ }^{[40]}$ These data demonstrate that, since the shrinkage occurred preferentially in the unaffected hemisphere, the midline shift tended to get worse. Thus, more research is needed to analyse its utility in patients with acute stroke.

\section{Elective craniotomies: Brain relaxation}

The term brain relaxation was first proposed by Hayes and Slocum to describe the content-space relationship of the intracranial cavity, after opening the dura during 
elective craniotomies. ${ }^{[41]}$ Contrary to the concept of ICP, it is a subjective estimation of the brain firmness, usually made by the surgeon, once the cranium has been opened. However, these concepts are intrinsically related, since the raised ICP results from an increased volume of the content that surpasses the capacity of the intracranial space. ${ }^{[41]}$

In the context of elective supratentorial craniotomies for brain tumour surgery, some authors have used $20 \%$ mannitol infusion at scalp incision, to provide intraoperative brain relaxation and facilitate the exposure of deep brain structures. ${ }^{[27,42,43]}$ In a randomised clinical trial, brain relaxation was evaluated after administering either 0.7 or $1.4 \mathrm{~g} / \mathrm{kg}$ of $20 \%$ mannitol at scalp incision, in patients undergoing supratentorial brain tumour craniotomy ${ }^{[13]}$ It was reported significantly better brain relaxation scores with higher doses, suggesting a dose-response relationship, particularly in patients with radiologic midline shift. However, the type and size of the craniotomies were not taken into account in this study. ${ }^{[13]}$

When compared to equiosmolar hypertonic saline (HTS) in the setting of patients with subarachnoid haemorrhage (SAH) undergoing craniotomy for aneurysm clipping, mannitol provided similar brain relaxation scores. ${ }^{[42]}$ Furthermore, neither mannitol nor HTS have demonstrated any improvement on ICU stays or hospital days. ${ }^{[4]]}$ Thus, although mannitol seems to be effective for brain relaxation at intravenous doses of $0.25-1 \mathrm{~g} / \mathrm{kg}^{\left[{ }^{[4]}\right]}$ its effects in this setting are still controversial and deserve further investigation.

\section{Traumatic brain injury}

In an animal model of post-traumatic diffuse brain oedema, Schilte et al. recently studied the structural and physiologic changes after inducing TBI in rats. ${ }^{[45]}$ Mannitol infusion ( $1 \mathrm{gm} / \mathrm{kg} 30 \mathrm{~min}$ after the injury) showed to improve the brain tissue oxygenation and venous oxygen saturation in the superior sagittal sinus $2 \mathrm{~h}$ after inducing the injury, compared to those who received normal saline. When caudoputamen samples were examined post-mortem, the percentage of capillaries surrounded by oedema was significantly lower in the mannitol group. These findings suggest that it can reverse ultrastructure changes induced by TBI, thereby optimising the oxygen utilisation by brain tissue in rodents. It is important to note, however, that BBB was not disrupted in these models. ${ }^{[45]}$

According to the Brain Trauma Foundation Guidelines Task Force, mannitol should be used to control ICP at doses between 0.25 and $1 \mathrm{~g} / \mathrm{kg}$ body weight in a single dose, administered over 20-30 min. ${ }^{[14,46]}$ There are however insufficient data to support regular administration over several days. ${ }^{[4,14,46]}$ Likewise, there is a lack of evidence to support the use of intermittent boluses or continuous infusion. ${ }^{[14]}$ In patients with TBI before ICP monitoring, it should be restricted to those with signs of transtentorial herniation or progressive neurologic deterioration. ${ }^{[46]}$

In a systematic review, the impact of mannitol on mortality in patients with acute TBI has been inconclusive. ${ }^{[47]}$ Results from the clinical trials are summarised in Table 2. Accordingly, the available evidence is insufficient to support the routine use of mannitol in patients with TBI.

\section{Mannitol versus hypertonic saline}

For decades, mannitol has been considered the gold standard for the treatment of ICP. However, some concerns have been raised regarding its side effects, and over the past few years, HTS has been proposed alternatively. ${ }^{[30]}$ In fact, one of the main advantages of HTS over mannitol is that it does not cause hypovolaemia, which is of particular importance in patients with TBI ${ }^{[30]}$ Thus, although the sodium concentration tends to normalise after $48 \mathrm{~h}$ regardless of the hypertonic solution used, ${ }^{[42]}$ the baseline sodium levels and the underlying disease can help the clinician to choose the hyperosmolar therapy.

HTS has been used in a range of concentrations of $1.7 \%-29.2 \%$, thereby making difficult to evaluate its optimal dose and concentration in clinical trials. ${ }^{[4,48]}$

\begin{tabular}{|c|c|c|c|c|c|c|}
\hline Author & Year & $\begin{array}{l}\text { Sample } \\
\text { size }\end{array}$ & Intervention group & Control group & $\begin{array}{l}\text { RR for death } \\
(95 \% \mathrm{CI})\end{array}$ & Follow-up \\
\hline $\begin{array}{l}\text { Schwartz } \\
\text { et al. }\end{array}$ & 1984 & 70 & $\begin{array}{l}\text { Mannitol 1g/kg plus } \\
\text { additional increments }\end{array}$ & $\begin{array}{l}\text { Pentobarbital } 10 \mathrm{mg} / \mathrm{kg} \\
\text { plus continuous infusion }\end{array}$ & $0.85(0.52-1.38)$ & 1 year \\
\hline Smith et al. & 1986 & 77 & $\begin{array}{l}\text { Mannitol clinical-guided } \\
\text { treatment }\end{array}$ & $\begin{array}{l}\text { Mannitol ICP-guided } \\
\text { treatment }\end{array}$ & $0.83(0.55-1.38)$ & 1 year \\
\hline Sayre et al. & 1996 & 44 & $\begin{array}{l}\text { Mannitol pre-hospital } \\
\text { administration }\end{array}$ & Placebo & $1.75(0.48-6.38)$ & $\begin{array}{l}2 \mathrm{~h} \text { after arrival } \\
\text { to hospital }\end{array}$ \\
\hline $\begin{array}{l}\text { Vialet } \\
\text { et al. }\end{array}$ & 2003 & 20 & $20 \%$ mannitol $2 \mathrm{ml} / \mathrm{kg}$ & $\begin{array}{l}\text { Hypertonic saline } 7.5 \% \\
2 \mathrm{ml} / \mathrm{kg}\end{array}$ & $1.25(0.47-3.33)$ & 3 months \\
\hline
\end{tabular}

$\mathrm{RR}=$ Relative risk, $\mathrm{Cl}=$ Confidence interval, $\mathrm{ICP}=$ Intracranial pressure 
Similar to mannitol, it can improve CBF by relaxing the arteriolar vascular smooth muscle and diminishing the cerebral endothelial cell oedema. Some side effects including electrolyte imbalances, volume overload, rebound intracranial hypertension and central pontine myelinolysis have been also described. ${ }^{[4]}$

The central pontine myelinolysis caused by a sharp increase in the sodium serum concentration is of particular concern when HTS is administered. ${ }^{[30]}$ Accordingly, plasma sodium concentration must be closely monitored, and values $>155 \mathrm{mmol} / \mathrm{L}$ should be avoided. Moreover, it should be administered through a central line catheter catheter, to avoid the risk of thrombophlebitis. ${ }^{[4]}$

Although the mechanisms to control raised ICP are similar, HTS is not related to AKI, hyperkalaemia or hyponatraemia. ${ }^{[48]}$ In addition, the reflection coefficient (a term used to describe the relative impermeability to the intact BBB) of HTS is slightly higher compared with mannitol (1.0 and 0.9, respectively). ${ }^{[8,30,44]}$ Therefore, the $\mathrm{CBF}$ is consistently improved, thereby counteracting hypoperfusion and vasospasm. ${ }^{[30]}$

In the setting of TBI, HTS appears to have a number of advantages, including plasma volume expansion, brain cell immune modulation, reduction of extracellular glutamate and CBF improvement. ${ }^{[30]}$ However, these theoretical advantages have not been supported by the available evidence, which is summarised in Table $3 .^{[49-56]}$ In the context of elective craniotomy for supratentorial tumours, equiosmolar doses of $20 \%$ mannitol and 3\% HTS seem to provide similar relaxation scores, whereas effectively improve ICP and $\mathrm{CPP}$, without significant differences in the haemodynamic response despite the higher urine output observed with mannitol. ${ }^{[43]}$

Data are limited in other scenarios because of the heterogeneity of the study population, the disparity of sodium formulations, differing inclusion and exclusion criteria and the small sample size of most clinical trials. Therefore, further research is warranted to determine the relative benefits of these two agents. In particular, whether it improves the CPP or modifies the neurological outcome irrespective its undeniable effects on the ICP, remains unknown. ${ }^{[14]}$

\section{CONCLUSION}

Mannitol has been used in several clinical scenarios in neuroanaesthesia. However, its main effects are dependent on the integrity of the BBB, and the available evidence is scarce to support its routine use in neurocritical patients unless the ICP is elevated despite first-line treatment. A better understanding of its osmotic effects impacting on the cardiovascular system, the kidney and the brain physiology, is essential to optimise its clinical use and improve its safety profile. In most instances, the decision to use mannitol or HTS should be carefully made based on the underlying disease, the sodium levels and the cardiovascular stability of the patient.

Whether mannitol can improve neurological outcomes or has any impact on mortality in patients with TBI is unknown. In addition, some questions remain unanswered regarding the optimal treatment regimen and the alternative use of HTS. Therefore, larger clinical trials are needed to address these crucial aspects of the treatment.

Table 3: Clinical trials evaluating the effectivity of mannitol compared to hypertonic saline in patients with severe traumatic brain injury and raised intracranial pressure

\begin{tabular}{|c|c|c|c|c|c|c|c|}
\hline Author & Year & $\begin{array}{l}\text { Sample } \\
\text { size }\end{array}$ & $\begin{array}{c}\text { Mannitol } \\
\text { dose (\%) }\end{array}$ & $\begin{array}{c}\text { HTS } \\
\text { dose }(\%)\end{array}$ & Outcome & Effect size & $P$ \\
\hline Vialet et al..$^{[51]}$ & 2003 & 20 & $\begin{array}{c}2 \mathrm{ml} / \mathrm{kg} \\
(20 \%)\end{array}$ & $\begin{array}{c}2 \mathrm{ml} / \mathrm{kg} \\
(7.5)\end{array}$ & $\begin{array}{l}\text { Number of } \\
\text { episodes } \\
\text { per day }\end{array}$ & $\begin{array}{l}\text { Mannitol: } 13.3 \pm 14.2^{*} \\
\text { HTS: } 6.8 \pm 5.5^{*}\end{array}$ & 0.02 \\
\hline $\begin{array}{l}\text { Francony } \\
\text { et al. }{ }^{[52]}\end{array}$ & 2008 & 20 & $\begin{array}{c}231 \mathrm{ml} \\
(20 \%)\end{array}$ & $\begin{array}{c}100 \mathrm{ml} \\
(7.45)\end{array}$ & $\begin{array}{l}\text { Difference } \\
\text { of means }\end{array}$ & $-4(95 \%$ CI-8.11-0.11) & 0.057 \\
\hline Oddo et al..$^{[53]}$ & 2009 & 42 & $\begin{array}{l}0.75 \mathrm{~g} / \mathrm{kg} \\
(25 \%)\end{array}$ & $\begin{array}{c}250 \mathrm{ml} \\
(7.5)\end{array}$ & $\mathrm{PbtO}_{2}^{\S}$ & $\begin{array}{l}\text { Mannitol: Decreased } 2.9 \mathrm{~mm} \mathrm{Hg} \\
\text { HTS: Increased } 13.1 \mathrm{~mm} \mathrm{Hg}\end{array}$ & $\begin{array}{l}>0.1 \\
<0.01\end{array}$ \\
\hline $\begin{array}{l}\text { Cottenceau } \\
\text { et al. }{ }^{[54]}\end{array}$ & 2011 & 47 & $\begin{array}{l}4 \mathrm{ml} / \mathrm{kg} \\
(20 \%)\end{array}$ & $\begin{array}{c}2 \mathrm{ml} / \mathrm{kg} \\
(7.5)\end{array}$ & $\begin{array}{l}\text { Difference } \\
\text { of means }\end{array}$ & $-1.30(95 \% \mathrm{CI}-6.33-3.73)^{\dagger}$ & 0.612 \\
\hline $\begin{array}{l}\text { Sakellaridis } \\
\text { et al. }{ }^{[55]}\end{array}$ & 2011 & $199:$ & $\begin{array}{l}2 \mathrm{ml} / \mathrm{kg} \\
(20 \%)\end{array}$ & $\begin{array}{c}0.42 \mathrm{ml} / \mathrm{kg} \\
(15)\end{array}$ & $\begin{array}{l}\text { Difference } \\
\text { of means }\end{array}$ & $-0.47(-2.38-1.44)^{\dagger}$ & 0.629 \\
\hline $\begin{array}{l}\text { Jagannatha } \\
\text { et al. }{ }^{[56]}\end{array}$ & 2016 & $450^{\vdots}$ & $\begin{array}{c}2.5 \mathrm{ml} / \mathrm{kg} \\
(20 \%)\end{array}$ & $\begin{array}{c}2.5 \mathrm{ml} / \mathrm{kg} \\
\text { (3) }\end{array}$ & Fall in ICP & $\begin{array}{l}\text { Mannitol: } 8.9 \pm 8.4 \\
\text { HTS: } 10.1 \pm 8.7\end{array}$ & 0.135 \\
\hline
\end{tabular}

${ }^{*}$ Mean $\pm \mathrm{SD}$. ${ }^{\dagger}$ Differences of means are reported two hours after the treatment, ${ }^{\star}$ Number of ICP episodes, ${ }^{\$} \mathrm{PbtO}$ : Brain tissue oxygen tension, "Results are given compared to baseline values at $2 \mathrm{~h}$. $\mathrm{HTS}=$ Hypertonic saline, $\mathrm{SD}=$ Standard deviation, $\mathrm{ICP}=$ Intracranial pressure, $\mathrm{Cl}=\mathrm{Confidence}$ interval 


\section{Financial support and sponsorship}

Nil.

\section{Conflicts of interest}

There are no conflicts of interest.

\section{REFERENCES}

1. Smith WW, Finkelstein N, Smith HW. Renal excretion of hexitols (sorbitol, mannitol, and dulcitol) and their derivatives (sorbitan, isomannide, and sorbide) and of endogenous creatinine-like chromogen in dog and man. J Biol Chem 1940;135:231-50.

2. Better OS, Rubinstein I, Winaver JM, Knochel JP. Mannitol therapy revisited (1940-1997). Kidney Int 1997;52:886-94.

3. Nissenson AR, Weston RE, Kleeman CR. Mannitol. West J Med 1979;131:277-84.

4. Shawkat H, Westwood MM, Mortimer A. Mannitol: A review of its clinical uses. Contin Educ Anaesth Crit Care Pain 2012;12:82-5.

5. WHO | WHO Model Lists of Essential Medicines. WHO; 2015. Available from: http://www.who.int/medicines/publications/ essentialmedicines/en/. [Last accessed on 2017 May 06].

6. Song SH, Vieille C. Recent advances in the biological production of mannitol. Appl Microbiol Biotechnol 2009;84:55-62.

7. Lin SY, Tang SC, Tsai LK, Yeh SJ, Shen LJ, Wu FL, et al. Incidence and risk factors for acute kidney injury following mannitol infusion in patients with acute stroke: A retrospective cohort study. Medicine (Baltimore) 2015;94:e2032.

8. White H, Cook D, Venkatesh B. The use of hypertonic saline for treating intracranial hypertension after traumatic brain injury. Anesth Analg 2006;102:1836-46.

9. Nomani AZ, Nabi Z, Rashid H, Janjua J, Nomani H, Majeed A, et al. Osmotic nephrosis with mannitol: Review article. Ren Fail 2014;36:1169-76.

10. Rabetoy GM, Fredericks MR, Hostettler CF. Where the kidney is concerned, how much mannitol is too much? Ann Pharmacother 1993;27:25-8.

11. Rudehill A, Lagerkranser M, Lindquist C, Gordon E. Effects of mannitol on blood volume and central hemodynamics in patients undergoing cerebral aneurysm surgery. Anesth Analg 1983;62:875-80.

12. Coté CJ, Greenhow DE, Marshall BE. The hypotensive response to rapid intravenous administration of hypertonic solutions in man and in the rabbit. Anesthesiology 1979;50:30-5.

13. Quentin C, Charbonneau S, Moumdjian R, Lallo A, Bouthilier A, Fournier-Gosselin MP, et al. A comparison of two doses of mannitol on brain relaxation during supratentorial brain tumor craniotomy: A randomized trial. Anesth Analg 2013;116:862-8.

14. Brain Trauma Foundation; American Association of Neurological Surgeons; Congress of Neurological Surgeons; Joint Section on Neurotrauma and Critical Care, AANS/CNS, Bratton SL, Chestnut RM, Ghajar J, McConnell Hammond FF, et al. Guidelines for the management of severe traumatic brain injury. II. Hyperosmolar therapy. J Neurotrauma 2007;24 Suppl 1:S14-20.

15. Fink ME. Osmotherapy for intracranial hypertension: Mannitol versus hypertonic saline. Continuum (Minneap Minn) 2012;18:640-54.

16. Doi K, Ogawa N, Suzuki E, Noiri E, Fujita T. Mannitol-induced acute renal failure. Am J Med 2003;115:593-4.

17. Kim MY, Park JH, Kang NR, Jang HR, Lee JE, Huh W, et al. Increased risk of acute kidney injury associated with higher infusion rate of mannitol in patients with intracranial hemorrhage. J Neurosurg 2014;120:1340-8.
18. Berry AJ, Peterson ML. Hyponatremia after mannitol administration in the presence of renal failure. Anesth Analg 1981;60:165-7.

19. Tsai SF, Shu KH. Mannitol-induced acute renal failure. Clin Nephrol 2010;74:70-3.

20. Dziedzic T, Szczudlik A, Klimkowicz A, Rog TM, Slowik A. Is mannitol safe for patients with intracerebral hemorrhages? Renal considerations. Clin Neurol Neurosurg 2003;105:87-9.

21. Hassan ZU, Kruer JJ, Fuhrman TM. Electrolyte changes during craniotomy caused by administration of hypertonic mannitol. J Clin Anesth 2007;19:307-9.

22. Fanous AA, Tick RC, Gu EY, Fenstermaker RA. Life-threatening mannitol-induced hyperkalemia in neurosurgical patients. World Neurosurg 2016;91:672.e5-9.

23. Flynn BC. Hyperkalemic cardiac arrest with hypertonic mannitol infusion: The strong ion difference revisited. Anesth Analg 2007;104:225-6.

24. Sharma J, Salhotra R. Mannitol-induced intraoperative hyperkalemia, a little-known clinical entity. J Anaesthesiol Clin Pharmacol 2012;28:546-7.

25. Seto A, Murakami M, Fukuyama H, Niijima K, Aoyama K, Takenaka I, et al. Ventricular tachycardia caused by hyperkalemia after administration of hypertonic mannitol. Anesthesiology 2000;93:1359-61.

26. Tisherman SA. Mannitol: It is not just for intracranial pressure any more! Maybe. Crit Care Med 2015;43:2267-8.

27. Ravussin $P$, Archer DP. The uses of mannitol in neuro-anaesthesia and neuro-intensive care. EurJ Anaesthesiol 2000;17:89-91.

28. Schrot RJ, Muizelaar JP. Mannitol in acute traumatic brain injury. Lancet 2002;359:1633-4.

29. Winkler SR, Munoz-Ruiz L. Mechanism of action of mannitol. Surg Neurol 1995;43:59.

30. Boone MD, Oren-Grinberg A, Robinson TM, Chen CC, Kasper EM. Mannitol or hypertonic saline in the setting of traumatic brain injury: What have we learned? Surg Neurol Int 2015;6:177.

31. Hemphill JC $3^{\text {rd }}$, Greenberg SM, Anderson CS, Becker K, Bendok BR, Cushman M, et al. Guidelines for the management of spontaneous intracerebral hemorrhage: A guideline for healthcare professionals from the American Heart Association/American Stroke Association. Stroke 2015;46:2032-60.

32. Dastur CK, Yu W. Current management of spontaneous intracerebral haemorrhage. Stroke and Vascular Neurology 2017:e000047.

33. Gigliuto CM, Stone KE, Algus M. The use of mannitol in intracerebral bleeds in the medical ICU. NJ Med 1991;88:48-51.

34. Kalita J, Misra UK, Ranjan P, Pradhan PK, Das BK. Effect of mannitol on regional cerebral blood flow in patients with intracerebral hemorrhage. J Neurol Sci 2004;224:19-22.

35. Misra UK, Kalita J, Ranjan P, Mandal SK. Mannitol in intracerebral hemorrhage: A randomized controlled study. J Neurol Sci 2005;234:41-5.

36. Wang $\mathrm{X}$, Arima $\mathrm{H}$, Yang J, Zhang $\mathrm{S}$, Wu G, Woodward $\mathrm{M}$, et al. Mannitol and outcome in intracerebral hemorrhage: Propensity score and multivariable intensive blood pressure reduction in acute cerebral hemorrhage trial 2 results. Stroke 2015;46:2762-7.

37. Shah M, Rasmussen J, Birnbaum L, Moomaw C, Sekar P, Osborne J, et al. Effect of hyperosmolar therapy on outcome following spontaneous intracerebral hemorrhage: The ERICH study (S25.007). Neurology 2014;82 10 Suppl:S25.007.

38. Jauch EC, Saver JL, Adams HP Jr., Bruno A, Connors JJ, Demaerschalk BM, et al. Guidelines for the early management of patients with acute ischemic stroke: A guideline for healthcare professionals from the American Heart Association/ American Stroke Association. Stroke 2013;44:870-947. 
39. Bereczki D, Mihálka L, Szatmári S, Fekete K, Di Cesar D, Fülesdi B, et al. Mannitol use in acute stroke: Case fatality at 30 days and 1 year. Stroke 2003;34:1730-5.

40. Videen TO, Zazulia AR, Manno EM, Derdeyn CP, Adams RE, Diringer MN, et al. Mannitol bolus preferentially shrinks non-infarcted brain in patients with ischemic stroke. Neurology 2001;57:2120-2.

41. Li J, Gelb AW, Flexman AM, Ji F, Meng L. Definition, evaluation, and management of brain relaxation during craniotomy. $\mathrm{Br} \mathrm{J}$ Anaesth 2016;116:759-69.

42. Sharma S, Grover VK, Mathew PJ. Mannitol versus hypertonic saline for intra-operative brain relaxation during aneurysm surgery. J Neuroanaesth Crit Care 2015;2:23-7.

43. Sokhal N, Rath GP, Chaturvedi A, Singh M, Dash HH. Comparison of $20 \%$ mannitol and 3\% hypertonic saline on intracranial pressure and systemic hemodynamics. J Clin Neurosci 2017. pii: S0967-586831498-9.

44. Wu CT, Chen LC, Kuo CP, Ju DT, Borel CO, Cherng CH, et al. A comparison of $3 \%$ hypertonic saline and mannitol for brain relaxation during elective supratentorial brain tumor surgery. Anesth Analg 2010;110:903-7.

45. Schilte C, Bouzat P, Millet A, Boucheix P, Pernet-Gallay K, Lemasson B, et al. Mannitol improves brain tissue oxygenation in a model of diffuse traumatic brain injury. Crit Care Med 2015;43:2212-8

46. Carney N, Totten AM, O'Reilly C, Ullman JS, Hawryluk GW, Bell MJ, et al. Guidelines for the management of severe traumatic brain injury, fourth edition. Neurosurgery 2017;80:6-15.

47. Wakai A, McCabe A, Roberts I, Schierhout G. Mannitol for acute traumatic brain injury. Cochrane Database Syst Rev 2013;8:CD001049.

48. Helmy A, Vizcaychipi M, Gupta AK. Traumatic brain injury: Intensive care management. Br J Anaesth 2007;99:32-42.

49. Li M, Chen T, Chen SD, Cai J, Hu YH. Comparison of equimolar doses of mannitol and hypertonic saline for the treatment of elevated intracranial pressure after traumatic brain injury: A systematic review and meta-analysis. Medicine (Baltimore) 2015;94:e736.

50. Kamel H, Navi BB, Nakagawa K, Hemphill JC $3^{\text {rd }}$, Ko NU. Hypertonic saline versus mannitol for the treatment of elevated intracranial pressure: A meta-analysis of randomized clinical trials. Crit Care Med 2011;39:554-9.

51. Vialet R, Albanèse J, Thomachot L, Antonini F, Bourgouin A, Alliez B, et al. Isovolume hypertonic solutes (sodium chloride or mannitol) in the treatment of refractory posttraumatic intracranial hypertension: $2 \mathrm{~mL} / \mathrm{kg} 7.5 \%$ saline is more effective than $2 \mathrm{~mL} / \mathrm{kg}$ 20\% mannitol. Crit Care Med 2003;31:1683-7.

52. Francony G, Fauvage B, Falcon D, Canet C, Dilou H, Lavagne P, et al. Equimolar doses of mannitol and hypertonic saline in the treatment of increased intracranial pressure. Crit Care Med 2008;36:795-800.

53. Oddo M, Levine JM, Frangos S, Carrera E, Maloney-Wilensky E, Pascual JL, et al. Effect of mannitol and hypertonic saline on cerebral oxygenation in patients with severe traumatic brain injury and refractory intracranial hypertension. J Neurol Neurosurg Psychiatry 2009;80:916-20.

54. Cottenceau V, Masson F, Mahamid E, Petit L, Shik V, Sztark F, et al. Comparison of effects of equiosmolar doses of mannitol and hypertonic saline on cerebral blood flow and metabolism in traumatic brain injury. J Neurotrauma 2011;28:2003-12.

55. Sakellaridis N, Pavlou E, Karatzas S, Chroni D, Vlachos K, Chatzopoulos K, et al. Comparison of mannitol and hypertonic saline in the treatment of severe brain injuries. J Neurosurg 2011;114:545-8.

56. Jagannatha AT, Sriganesh K, Devi BI, Rao GS. An equiosmolar study on early intracranial physiology and long term outcome in severe traumatic brain injury comparing mannitol and hypertonic saline. J Clin Neurosci 2016;27:68-73. 